\title{
Managing Dyspepsia in a Primary Care Setting
}

\author{
A. Kenneth Musana, MD; Steven H. Yale, MD and Kevin A. Lang, MD
}

\section{Keywords:}

Dyspepsia,

Nonulcerative dyspepsia,

Management,

Endoscopy
Reprint Requests:

Steven H. Yale, MD

Department of Internal Medicine

Marshfield Clinic

1000 North Oak Avenue

Marshfield, WI 54449

Telephone: 7I5-387-5436

Fax: 715-389-3808

Email:yale.steven@mcrf.mfldclin.edu

Received: March 23, 2006

Revised: July 14, 2006

Accepted: July 26, 2006

$$
\underset{\substack{c a r \\ \text { sate }}}{\cos }
$$

D care physicians and is found in approximately $20 \%$ to $25 \%$ of adults in the United States. ${ }^{1}$ Dyspepsia is characterized by chronic or recurrent upper abdominal pain or discomfort and is often associated with one or more of the following symptoms occurring at any given time: early satiety, a burning sensation in the upper abdomen, upper abdominal fullness or bloating and/or nausea. ${ }^{2}$ In patients presenting with predominant or frequent (i.e., more than once a week) symptoms of heartburn, gastroesophageal reflux disease (GERD) is the primary diagnosis that should be considered until proven otherwise. ${ }^{3}$

Symptoms of dyspepsia are commonly present in patients with GERD, peptic ulcer disease (PUD) and gastric or esophageal dysmotility disorders. Functional or nonulcerative dyspepsia is a condition characterized by the presence of dyspepsia symptoms in the absence of ultrasonographic and endoscopic evidence of PUD, gallbladder disease or other organic etiologies. It has been suggested that the management of dyspepsia often depends upon the patient's symptoms and underlying etiology. Therefore, dyspepsia has been subcatagorized into several groups such as ulcer-like, reflux-like, dysmotility-like and nonspecific dyspepsia ${ }^{1}$ and treatment directed on the basis of the patient's most predominant symptom. Symptom subgrouping alone, however, cannot reliably distinguish patients with underlying PUD or other organic disease from patients with functional dyspepsia and has not been found to be helpful in determining treatment options. ${ }^{4}$

The best approach to the management of dyspepsia remains controversial. Management should be individualized and take into account factors such as the accuracy of available noninvasive diagnostic tests, the prevalence of Helicobacter pylori infection in the community, the accessibility and cost of endoscopy, the risks vs. benefits to the patient, and the patient's acceptability of a given approach. This article reviews the current recommendations for the management of patients with dyspepsia.

\section{EVALUATION OF DYSPEPSIA}

\section{History}

The patient history should assess the quality, duration and severity of symptoms, as well as the presence of other associated symptoms. A list of current medications, especially nonsteroidal anti-inflammatory drugs (NSAIDs), over-the-counter 
medications and herbal remedies should be collected. A family history of PUD, alcohol use and psychiatric or psychosocial disorders should be noted.

\section{Endoscopy}

Endoscopy is recommended in patients with dyspepsia who have alarm symptoms suggestive of potentially serious underlying conditions such as PUD, gastric/esophageal cancer and other rare upper gastrointestinal (GI) diseases (table 1). ${ }^{1}$ New onset dyspepsia in any patient older than 55 years of age also warrants endoscopy because of the higher incidence of gastric cancer found in patients with advancing age.

Studies from open-access endoscopy practices and outpatient series demonstrate that only a few patients with dyspepsia in fact have PUD, reflux esophagitis and gastric cancer, particularly in western populations. ${ }^{5,6}$ In a series of 228 cases of confirmed upper GI cancers who originally presented with uncomplicated dyspepsia symptoms, Sundar and colleagues 7 identified 5 patients with dyspepsia and no alarm symptoms that had resectable upper GI malignancies. They concluded that endoscopic investigation was not useful in diagnosing cancer at an early stage.

Phull and colleagues ${ }^{8}$ conducted a retrospective study in Scotland to quantify the risk of missing an upper GI malignancy if the threshold for urgent endoscopy in uncomplicated dyspepsia was increased from 45 to 55 years of age. Of the 3,293 patients diagnosed with upper GI cancer, only $290(8.8 \%)$ were $<55$ years and only 21 of these 290 $(0.6 \%$ of all patients) had no alarm symptoms. They concluded that upper GI malignancy is uncommon before 55 years of age and most of the patients subsequently found to have a malignancy presented with alarm symptoms. They noted that increasing the age of endoscopy from 45 to 55 years of age would not adversely impact the diagnosis of upper GI malignancy.

Most patients undergoing endoscopy are diagnosed as having nonulcerative dyspepsia. Thus, it is important to identify noninvasive tests with high sensitivity, specificity and negative predictive value that can be used to exclude patients without underlying pathological conditions.

\section{Testing for $\boldsymbol{H}$. pylori}

H. pylori infection is a major risk factor for PUD, especially when the use of NSAIDs has been excluded. The rationale for H. pylori testing is to identify those patients with dyspepsia who have underlying PUD. Although most patients with H. pylori infection do not develop PUD, as many as $95 \%$ of patients with duodenal ulcers and $80 \%$ with gastric ulcers have an $H$. pylori infection.

The prevalence of $H$. pylori varies in different populations. Higher rates are found in populations with lower social economic status. In developed countries, the prevalence is higher in the immigrant population. Using serologic testing, the prevalence in the United States was 9.4\% in submarine
Table 1. Alarm symptoms in dyspepsia necessitating evaluation for peptic ulcer disease or gastrointestinal malignancy.

\section{Alarm symptoms in dyspepsia*}

Age $>55$ years

Gastrointestinal bleeding

Anemia

Palpable abdominal mass

Progressive dysphagia

Early satiety

Anorexia

Odynophagia

Persistent vomiting

Previous documented peptic ulcer

Previous gastric surgery or malignancy

Family history of gastrointestinal cancer

Unexplained weight loss (>10\% of body weight)

Lymphadenopathy

* American College of Gastroenterology Guidelines for the Management of Dyspepsia 2005

workers, ${ }^{9} 26.2 \%$ in non-Hispanic caucasians, $52.7 \%$ among non-Hispanic African Americans and $61.6 \%$ in Mexican Americans. ${ }^{10}$ In the province of Ourense, Spain, the prevalence rate of $H$. pylori infection was approximately $69 \%$ in the general adult population ${ }^{11}$ and in the Czech Republic, it was approximately $41 \% .^{12}$

Noninvasive tests for $H$. pylori infection are important in primary care, both for the initial diagnosis of $H$. pylori infection and to confirm eradication of existing infection (table 2). The results of $H$. pylori noninvasive testing depend on the positive and negative predictive values and hence the prevalence of $H$. pylori in that population.

The urea breath test (UBT) and the stool antigen test are the most accurate noninvasive indirect diagnostic tests for $H$. pylori infection and are recommended especially in low prevalence populations. ${ }^{13,14}$ Unlike serological tests that are only markers for exposure to $H$. pylori and do not differentiate current from previous infection, the UBT and the stool antigen test detect active infection. According to the American College of Gastroenterology guidelines, the UBT is the best nonendoscopic test for documenting $H$. pylori infection. ${ }^{15}$ 
Table 2. Noninvasive testing for Helicobacter pylori.

\begin{tabular}{lccc}
\hline Test & Sensitivity (\%) & Specificity (\%) & Cost to patient (US \$)* $^{*}$ \\
\hline Urea breath test & $88-95$ & $95-100$ & 220 \\
Fecal antigen test & 90 & 95 & 81.10 \\
Serology $(\operatorname{lgG}) \dagger$ & $90-100$ & $76-96$ & 119 \\
Serology $(\lg \mathrm{A})$ & $90-100$ & $76-96$ & 80.94 \\
\hline
\end{tabular}

* Marshfield Clinic laboratories

† Wilcox MH, Dent TH, Hunter JO, Gray JJ, Brown DF, Wight DG, Wraight EP. Accuracy of serology for the diagnosis of Helicobacter pylori infection-a comparison of eight kits. J Clin Pathol 1996;49:373-376.

Urea Breath Test

There are two UBTs that have been approved by the Federal Drug Administration for use in the United States: the non-radioactive ${ }^{13} \mathrm{C}$ test (Meretek, Otsuka Pharmaceuticals, Tokyo, Japan) and the radioactive ${ }^{14} \mathrm{C}$ test (Tri-Med, Ballard Medical Devices, Subiaco, Western Australia). They can both be performed in about 20 minutes and have sensitivities of approximately $88 \%$ to $95 \%$ and specificities of approximately $95 \%$ to $100 \% .{ }^{15}$ False-positive results are rare but may be observed in patients who are taking antisecretory drugs, bismuth or antibiotics. Thus, patients should be off antibiotics for at least 4 weeks and off proton pump inhibitors (PPIs) for at least 2 weeks prior to undergoing these tests.

\section{Stool Antigen Test}

Enzyme immunoassay can be conducted on stool to determine $H$. pylori infection ${ }^{16}$ and is considered a direct test of $H$. pylori because it detects the presence of bacterial antigens in the stool. Stool antigen tests have both sensitivities and specificities of approximately $92 \% .17,18$

\section{Serologic Testing}

Serologic testing is an indirect test for $H$. pylori infection that detects IgG or IgA antibodies to $H$. pylori and has variable specificity. It is a cost-effective tool, particularly in populations in which the prevalence of $H$. pylori is high. However, it may lead to the over-treatment of patients due to the high rate of false-positive test results. ${ }^{19}$ Loy and colleagues $^{20}$ performed a meta-analysis of 21 studies of different commercial kits for $\mathrm{H}$. pylori serology and found an overall sensitivity of $85 \%$ and specificity of $79 \%$. IgG antibodies are likely to remain elevated months after treatment for $H$. pylori infection. Thus, serologic testing for $H$. pylori is unlikely to be very useful for determining whether earlier eradication treatment was successful. 19

\section{TREATMENT APPROACHES IN UNINVESTIGATED DYSPEPSIA}

Patients presenting with dyspepsia who have not had an endoscopic evaluation are described as having "uninvestigated dyspepsia," since the presence of an underlying lesion has not been excluded. There are several approaches to the treatment of dyspepsia which may need to be individualized depending on the prevalence of H. pylori and PUD in the population: the patient's predominant symptoms, the effectiveness of previous therapy in improving dyspeptic symptoms, the patient's family history of PUD or gastric cancer, the positive predictive values of noninvasive tests, and in some cases, patient preference (figure 1).

\section{Presence of Alarm Symptoms}

In patients presenting with alarm symptoms or in those older than 55 years of age, prompt referral for specialist evaluation and endoscopy is recommended. This is also the treatment strategy in communities where the incidence of gastric or esophageal cancers is high. ${ }^{3}$

\section{Non-Prescription Empirical Pharmacotherapy}

For patients younger than 55 years of age without alarm symptoms, a "wait-and-see" strategy of patient reassurance, education and use of over-the-counter antacids, $\mathrm{H}_{2}$-blockers or PPIs is an acceptable approach. ${ }^{3}$ Patients who fail to respond should be re-evaluated.

\section{Full-Dose or High-Dose Antisecretory Therapy}

The American College of Gastroenterology suggests that false-positive test results are common in populations with very low prevalence rates of $H$. pylori, thus empiric treatment, such as acid suppression therapy, can be initiated in these populations. ${ }^{3}$ An empiric trial of antisecretory therapy should be administered for 6 to 8 weeks. Those who fail to respond or those with early relapse of symptoms should be referred for specialist evaluation and endoscopy. ${ }^{21}$ With their widespread availability and their demonstrated efficacy and safety, PPIs are now the recommended first-line antisecretory therapy in uninvestigated dyspepsia. ${ }^{22}$ Studies have looked at the efficacy of cisapride in dyspepsia; however, this medication is no longer available in the United States because of potential cardiac adverse side effects. No trials have studied the use of other prokinetic agents, such as metoclorpropamide, tegaserod or domperidone in uninvestigated dyspepsia. 


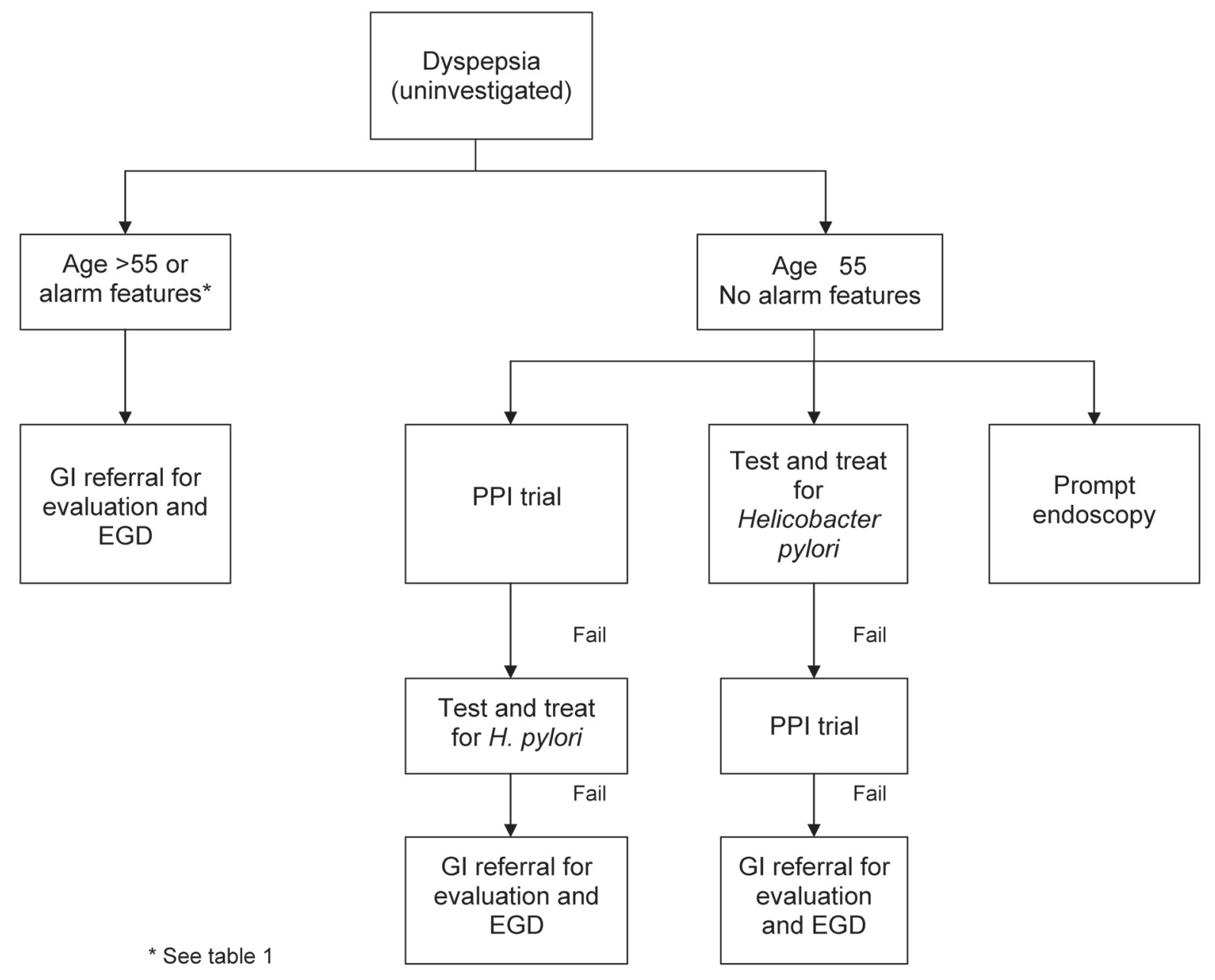

Figure 1. Algorithm for the management of uninvestigated dyspepsia.

The administration of inadequate treatment to patients with H. pylori PUD is a primary concern related to the use of empirical antisecretory therapy. Cost effectiveness is another main concern, especially if patients are ultimately referred for endoscopy. ${ }^{23}$

\section{H. pylori "Test-and-Treat" as the Initial Strategy}

"Test-and-treat" is the most widely recommended approach to management of uninvestigated dyspepsia, particularly in populations in which the prevalence of $H$. pylori is high. ${ }^{3}$ Randomized, controlled trials have shown that a "test-and-treat" strategy for $H$. pylori is a cost effective approach for patients with dyspepsia who are seen in primary care settings and have not undergone any previous evaluations, such as endoscopy or radiographic studies. ${ }^{24,25}$ Patients who test positive for H. pylori by means of noninvasive tests are treated with an appropriate $H$. pylori eradication regime. Those who test negative receive antisecretory therapy. The main goal of the "test-and-treat" strategy is to eradicate H. pylori infection that has been associated with PUD and consequently decrease the incidence of the potential complications of PUD, such as bleeding and perforation. $H$. pylori eradication has been shown to result in a reduction in the prevalence of PUD on endoscopy. Nervi and colleagues ${ }^{26}$ demonstrated a statistically significant decrease in the prevalence of ulcers, from $12.7 \%$ to $6.3 \%(P<0.001)$ in Padova, Italy and from $15.6 \%$ to $12 \%(P<0.001)$ in Parma, Italy.

The H. pylori "test-and-treat" approach can also be modified such that an antisecretory regimen is prescribed first, and H. pylori testing is reserved for those who do not respond. Alternatively, for cases in which $H$. pylori eradication did not effectively relieve initial symptoms, a course of high-dose antisecretory therapy is empirically provided (figure 1).

A major drawback of the "test-and-treat" approach is that treatment of $H$. pylori infection in patients with dyspepsia leads to symptom resolution for only a minority of these patients. Chiba et $\mathrm{al}^{27}$ conducted a randomized, placebo-controlled trial in which 294 patients with $H$. pylori were treated either with omeprazole plus antibiotics or omeprazole plus placebo for 1 week. Twelve months post-treatment, eradication of $H$. pylori resulted in no symptoms or minimal symptoms in 50\% of the patients as compared to $36 \%$ of those in the placebo arm. In patients with no symptom resolution, a trial of antisecretory therapy (if this has not been tried) or referral for specialist 
evaluation can be considered. Post-therapy testing is not recommended in dyspepsia; however, it is considered important in a subgroup of patients with complicated PUD.

\section{Initial Endoscopy with Biopsy of Suspicious Lesions}

In patients $>55$ years of age, an initial endoscopy with biopsy of suspicious lesions is the recommended approach to management of dyspepsia. However, it can also be used for all patients with dyspepsia as studies have shown endoscopy to be reassuring to patients, ${ }^{28-30}$ leading to reduced use of medication and physician visits. ${ }^{31,32}$ The disadvantage of endoscopy is that it is an invasive procedure with potential complications and would be costly if all patients with dyspepsia were referred. Although it is often recommended, some studies have shown that endoscopy is not superior to empirical treatment strategies. ${ }^{33}$ Moreover, a systematic review of the literature concluded that endoscopy alone did not improve patient outcomes in dyspepsia. ${ }^{34}$ Cost effectiveness analyses looking at prompt endoscopy versus "test-and-treat" for uninvestigated dyspepsia have not revealed a cost advantage to endoscopy. ${ }^{35-37}$

\section{Investigational Therapies}

Holtmann and colleagues ${ }^{38}$ investigated the use of itopride, a dopamine D2 antagonist with acetylcholinesterase effects, in 523 patients. They demonstrated that itopride was superior to placebo in symptom relief with an approximately $50 \%$ improvement in the symptom score for the treatment group compared to placebo. However, a dose response was not demonstrated. They concluded that additional studies were needed to further evaluate the utility and safety of itopride use in the treatment of dyspepsia.

\section{SUMMARY}

Dyspepsia is a common presenting complaint in primary care. There are several treatment options available for the management of this condition, and the decision of which approach to take depends on the incidence of esophageal or gastric cancer in the community, patient demographics, patients' level of concern regarding symptoms and availability of endoscopy services. There are no data that clearly indicate the superiority of one option over the others. However, it is agreed that any patient over 55 years of age or any patient with alarm symptoms should undergo prompt endoscopy for the purposes of excluding a GI malignancy.

\section{REFERENCES}

1. Talley NJ, Zinsmeister AR, Schleck CD, Melton LJ $3^{\text {rd }}$ Dyspepsia and dyspepsia subgroups: a population-based study. Gastroenterology 1992;102(4 Pt 1):1259-1268.

2. Drossman DA, Corazziari E, Talley NJ, Thompson WG, Whitehead WE. Rome II. The functional gastrointestinal disorders. $2^{\text {nd }}$ ed. McLean, VA: Degnon Associates; 2000.

3. Talley NJ, Vakil N; Practice Parameters Committee of the American College of Gastroenterology. Guidelines for the management of dyspepsia. Am J Gastroenterol 2005;100:2324-2337.
4. Thomson AB, Barkun AN, Armstrong D, Chiba N, White RJ, Daniels S, Escobedo S, Chakraborty B, Sinclair P, Van Zanten SJ. The prevalence of clinically significant endoscopic findings in primary care patients with uninvestigated dyspepsia: the Canadian Adult Dyspepsia Empiric Treatment - Prompt Endoscopy (CADET-PE) study. Aliment Pharmacol Ther 2003;17:1481-1491.

5. Voutilainen M, Mantynen T, Kunnamo I, Juhola M, Mecklin JP, Farkkila M. Impact of clinical symptoms and referral volume on endoscopy for detecting peptic ulcer and gastric neoplasms. Scand J Gastroenterol 2003;38:109-113.

6. Westbrook JI, Talley NJ. Diagnostic investigation rates and use of prescription and non-prescription medications amongst dyspeptics: a population-based study of 2300 Australians. Aliment Pharmacol Ther 2003;17:1171-1178.

7. Sundar N, Muraleedharan V, Pandit J, Green JT, Crimmins R, Swift GL. Does endoscopy diagnose early gastrointestinal cancer in patients with uncomplicated dyspepsia? Postgrad Med J 2006;82:52-54.

8. Phull PS, Salmon CA, Park KG, Rapson T, Thompson AM, Gilbert FJ. Age threshold for endoscopy and risk of missing upper gastrointestinal malignancy — data from the Scottish audit of gastric and oesophageal cancer. Aliment Pharmacol Ther 2006;23:229-233.

9. Jackman RP, Schlichting C, Carr W, Dubois A. Prevalence of Helicobacter pylori in United States Navy submarine crews. Epidemiol Infect 2006;134:460-464.

10. Everhart JE, Kruszon-Moran D, Perez-Perez GI, Tralka TS, McQuillan G. Seroprevalence and ethnic differences in Helicobacter pylori infection among adults in the United States. J Infect Dis 2000;181:1359-1363.

11. Macenlle Garcia R, Gayoso Diz P, Sueiro Benavides RA, Fernandez Seara J. Prevalence of Helicobacter pylori infection in the general adult population of the province of Ourense. Rev Esp Enferm Dig 2006;98:241-248.

12. Bures J, Kopacova M, Koupil I, Vorisek V, Rejchrt S, Beranek M, Seifert B, Pozler O, Zivny P, Douda T, Kolesarova M, Pinter M, Palicka V, Holcik J; European Society for Primary Care Gastroenterology. Epidemiology of Helicobacter pylori infection in the Czech Republic. Helicobacter 2006;11:56-65.

13. Thijs JC, van Zwet AA, Thijs WJ, Oey HB, Karrenbeld A, Stellaard F, Luijt DS, Meyer BC, Kleibeuker JH. Diagnostic tests for Helicobacter pylori: a prospective evaluation of their accuracy, without selecting a single test as the gold standard. Am J Gastroenterol 1996;91:2125-2129.

14. Gatta L, Ricci C, Tampieri A, Vaira D. Non-invasive techniques for the diagnosis of Helicobacter pylori infection. Clin Microbiol Infect 2003;9:489-496.

15. Howden CW, Hunt RH. Guidelines for the management of Helicobacter pylori infection. Ad Hoc Committee on Practice Parameters of the American College of Gastroenterology. Am J Gastroenterol 1998;93:2330-2338.

16. Vaira D, Vakil N, Menegatti M, van't Hoff B, Ricci C, Gatta L, Gasbarrini G, Quina M, Pajares Garcia JM, van Der Ende A, van Der Hulst R, Anti M, Duarte C, Gisbert JP, Miglioli M, Tytgat G. The stool antigen test for detection of Helicobacter pylori after eradication therapy. Ann Intern Med 2002;136:280-287.

17. Gisbert JP, Pajares JM. Diagnosis of Helicobacter pylori infection by stool antigen determination: a systematic review. Am J Gastroenterol 2001;96:2829-2838.

18. Endoscopy in the evaluation of dyspepsia. Health and Public Policy Committee, American College of Physicians. Ann Intern Med 1985;102:266-269.

19. Ho B, Marshall BJ. Accurate diagnosis of Helicobacter pylori. Serologic testing. Gastroenterol Clin North Am 2000;29:853862 . 
20. Loy CT, Irwig LM, Katelaris PH, Talley NJ. Do commercial serological kits for Helicobacter pylori infection differ in accuracy? A meta-analysis. Am J Gastroenterol 1996;91:1138-1144.

21. Vaira D, Vakil N. Blood, urine, stool, breath, money, and Helicobacter pylori. Gut 2001;48:287-289.

22. Moayyedi P, Soo S, Deeks J, Delaney B, Innes M, Forman D. Pharmacological interventions for non-ulcer dyspepsia. Cochrane Database Syst Rev 2004;18:CD001960.

23. Talley NJ. Dyspepsia: management guidelines for the millennium. Gut 2002;50:72-78.

24. Lassen AT, Pedersen FM, Bytzer P, Schaffalitzky de Muckadell OB. Helicobacter pylori test-and-eradicate versus prompt endoscopy for management of dyspeptic patients: a randomised trial. Lancet 2000;356:455-460.

25. Delaney B, Ford AC, Forman D, Moayyedi P, Qume M. Initial management strategies for dyspepsia. Cochrane Database Syst Rev 2005;19:CD001961.

26. Nervi G, Liatopoulou S, Cavallaro LG, Gnocchi A, Dal-Bo N, Rugge M, Iori V, Cavestro GM, Maino M, Colla G, Franze A, Di Mario F. Does Helicobacter pylori infection eradication modify peptic ulcer prevalence? A 10 years' endoscopical survey. World J Gastroenterol 2006;12:2398-2401.

27. Chiba N, Van Zanten SJ, Sinclair P, Ferguson RA, Escobedo S, Grace E. Treating Helicobacter pylori infection in primary care patients with uninvestigated dyspepsia: the Canadian adult dyspepsia empiric treatment-Helicobacter pylori positive (CADET-Hp) randomised controlled trial. BMJ 2002;324:1012-1016.

28. Wiklund I, Glise H, Jerndal P, Carlsson J, Talley NJ. Does endoscopy have a positive impact on quality of life in dyspepsia? Gastrointest Endosc 1998;47:449-454.

29. Quadri A, Vakil N. Health-related anxiety and the effect of open-access endoscopy in US patients with dyspepsia. Aliment Pharmacol Ther 2003;17:835-840.

30. Rabeneck L, Wristers K, Souchek J, Ambriz E. Impact of upper endoscopy on satisfaction in patients with previously uninvestigated dyspepsia. Gastrointest Endosc 2003;57:295299.

31. Hungin AP, Thomas PR, Bramble MG, Corbett WA, Idle N, Contractor BR, Berridge DC, Cann G. What happens to patients following open access gastroscopy? An outcome study from general practice. Br J Gen Pract 1994;44:519521.

32. Graham DY, Opekun AR, Yamaoka Y, Osato MS, el-Zimaity HM. Early events in proton pump inhibitor-associated exacerbation of corpus gastritis. Aliment Pharmacol Ther 2003; 17:193-200.

33. Lewin van den Broek NT, Numans ME, Buskens E, Verheij TJ, de Wit NJ, Smout AJ. A randomised controlled trial of four management strategies for dyspepsia: relationships between symptom subgroups and strategy outcome. Br J Gen Pract 2001;51:619-624.

34. Ofman JJ, Rabeneck L. The effectiveness of endoscopy in the management of dyspepsia: a qualitative systematic review. Am J Med 1999;106:335-346.

35. Laheij RJ, Hermsen JT, Jansen JB, Horrevorts AM, Rongen RJ, Van Rossum LG, Witteman E, de Koning RW. Empirical treatment followed by a test-and-treat strategy is more costeffective in comparison with prompt endoscopy or radiography in patients with dyspeptic symptoms: a randomized trial in a primary care setting. Fam Pract 2004;21:238-243.

36. Klok RM, Arents NL, de Vries R, Thijs JC, Brouwers JR, Kleibeuker JH, Postma MJ. Economic evaluation of a randomized trial comparing Helicobacter pylori test-and-treat and prompt endoscopy strategies for managing dyspepsia in a primary-care setting. Clin Ther 2005;27:1647-1657.
37. Ford AC, Qume M, Moayyedi P, Arents NL, Lassen AT, Logan RF, McColl KE, Myres P, Delaney BC. Helicobacter pylori "test and treat" or endoscopy for managing dyspepsia: an individual patient data meta-analysis. Gastroenterology 2005; 128:1838-1844.

38. Holtmann G, Talley NJ, Liebregts T, Adam B, Parow C. A placebo-controlled trial of itopride in functional dyspepsia. $\mathrm{N}$ Engl J Med 2006;354:832-840.

\section{AUTHOR AFFILIATIONS}

A. Kenneth Musana, MD, MSc

Department of Internal Medicine

Marshfield Clinic

Marshfield, Wisconsin USA

Steven H. Yale, $M D$

Department of Internal Medicine, Marshfield Clinic

Clinical Research Center,

Marshfield Clinic Research Foundation

Marshfield, Wisconsin USA

Kevin C. Lang, MD

Department of Gastroenterology

Marshfield Clinic

Marshfield, Wisconsin USA

Erratum

\section{Outpatient Practice Management Tips: Megaloblastic Anemia and Other Causes of Macrocytosis (Clin Med Res 2006;3:236-24I)}

\author{
Florence Aslinia, MD; Joseph J. Mazza, MD, MACP; and \\ Steven H. Yale, MD, FACP'
}

The original article to which this erratum refers was published in the September 2006 issue of Clinical Medicine \& Research (Clin Med Res 2006; 3:236-241).

The authors have reported the panels of figure 1 were printed in the wrong order. Figure $1 \mathrm{~A}$ in the text correctly corresponds to figure legend $1 \mathrm{~B}$, and figure $1 \mathrm{~B}$ correctly corresponds to figure legend $1 \mathrm{~A}$.

${ }^{\dagger}$ Address correspondence to: Steven H. Yale, MD, FACP, Department of Internal Medicine, Marshfield Clinic, $1000 \mathrm{~N}$. Oak Ave., Marshfield, WI 54449. Tel: 715-387-5436;

Fax: 715-389-3808; Email: yale.steven@mcrf.mfldclin.edu. 